\title{
Investigating coaching behaviors during the COVID-19 pandemic: a case study within a case study
}

Jonathan Glen Julie Gordon David Lavallee

Accepted author manuscript version reprinted, by permission, from Case Studies in Sport and Exercise Psychology, 2020, 4(1): pp.125-133, https://doi.org/10.1123/cssep.2020-0014

(C) Human Kinetics, Inc. 
Running Head: COVID-19 PANDEMIC

Investigating Coaching Behaviors during the COVID-19 Pandemic: A Case Study within a Case Study 


\begin{abstract}
The purpose of this case study is to offer reflections for both applied researchers and practitioners on our experiences of investigating coaching behaviors during the COVID-19 pandemic. The case is based on the delivery of remote, online tennis coaching sessions to children over a period of three weeks. Questionnaire, observation, and focus group data were collected from tennis players, coaches, and parents/guardians. Analyses revealed similarities and differences with previous investigations measuring coaching behaviors, as well as the perceived effectiveness of sports coaching in an online environment. Novel insights and recommendations for applied researchers and practitioners in sport and exercise psychology are highlighted, including the importance of staying connected during the pandemic, keeping players and parents motivated, and creativity. We consider the context of conducting a case study into coaching behaviors during the COVID-19 pandemic, itself, and conclude by providing reflections on our case study within the case study of COVID-19. These include enhanced communication as it was easier to connect with each other, the nature of the online delivery improving pre-session preparation, and the research process being relatively more straightforward to implement, all due to barriers being removed as a direct result of COVID-19 quarantine, stay-at-home restrictions.
\end{abstract}

Keywords: coach, coronavirus, SARS-CoV-2, sports 
Investigating Coaching Behaviors during the COVID-19 Pandemic: A Case Study within a Case Study

\section{Context}

The COVID-19 pandemic caused by SARS-CoV-2 coronavirus has impacted many aspects of society, including sports. Many sporting events have been either cancelled or postponed as a result, including the 2020 Summer Olympic and Paralympic Games, which have been postponed until 2021. Social distancing measures, including restrictions around public gatherings, put in place by many governments have closed schools and prevented many sports activities for children from operating as normal. Some governments around the world (e.g., New South Wales in Australia) have allowed individual sports such as tennis and golf to continue provided the local public health orders are complied with. Other Governments have issued stricter measures to prevent the spread of the virus which have included closing all sports facilities. In the United Kingdom, where this case study is situated, the Government issued measures to reduce day-to-day contact with other people on 23 March 2020 for an initial period of three weeks, which subsequently was extended for seven weeks in total (United Kingdom Government, 2020). This included ordering the closure of certain business and venues, including indoor and outdoor leisure facilities as well as communal places within parks, such as playgrounds, sports courts, and outdoor gyms.

In response to the measures put in place, many sports organizations initiated the delivery of remote, on-line coaching sessions. This involved a wide range of coaching activities, including video coaching and training apps (Child Protection and Sport Unit, 2020). Julie (second author) works as a coach at a tennis club in Scotland and initiated a remote, on-line coaching program delivered by nine coaches for 23 children during the initial three-week period when tennis facilities were closed ( $30^{\text {th }}$ March until $20^{\text {th }}$ April 2020). Julie has a master's degree in psychology of sport and, at the time of the case study, was enrolled on a doctoral degree in sport and exercise psychology. Julie had already invited Jonny (first author) and David (third author) to investigate 
coaching behavior in tennis prior to the COVID-19 pandemic. This research was in the planning stage when the pandemic occurred, so rather than cancel the project, Julie invited Jonny and David to observe coaching behavior delivered through an online program.

Our experiences have been informed by our approaches to research and practice. Jonny has an undergraduate degree in psychology and sport studies, a master's degree in sports coaching, and is conducting doctoral research on coaching behavior. He has significant experience of measuring and coding coach behavior employing validated instruments (e.g., Arizona State University Observation Instrument; Lacy \& Darst, 1984). He is also a qualified Union of European Football Association (UEFA) A coach, head academy football science, and Under-15 coach of a professional soccer team in Scotland. David's experience has been shaped through his applied research in sport settings over a 25 -year career. Julie has worked in the sports industry for 25 years and is an accredited Lawn Tennis Association (LTA) Level 5 Master Club Coach. Her approach to practice is humanistic (Nelson, Cushion, Potrac, \& Groom, 2014).

Jonny and David have an axiology that values research that has impact on practice, and therefore their applied research orientates towards pragmatist epistemology with constructivism as an ontological approach (e.g., Glen \& Lavallee, 2019). In line with a constructivist paradigm, this approach asserts learning is contextual and an active process in which individuals are influenced by the interaction of their prior knowledge, sensory input, and new information (Vygotsky, 1978). Sports coaches, therefore, present authentic, real-world experiences so the individuals they are coaching can construct meaning out of the activities (Schinke, McGannon, \& Smith, 2014).

This case study is underpinned by a broad theoretical foundation, given the lack of an empirical evidence base in sport and the agents involved (viz., coaches, athletes, parents/guardians, and researchers). We have drawn upon the work of Schultze and Brooks (2019) on social presence in virtual environments, and Zhao's (2003) concept of copresence that considers being with others as compared to the sense of being with others. We have also drawn upon the recent work by Bennett 
(2020) exploring the experiences of elite athletes being coached via video calling technology, although not during the COVID-19 pandemic.

Our case study had three fundamental aims. Firstly, we aimed to analyse coaching behaviors of tennis coaches delivered to children within an online environment and explore how these compared to face-to-face delivery. We also aimed to investigate the perceived effectiveness of remote, online tennis coaching sessions from the perspective of coaches and parents/guardians. Finally, we aimed to identify key factors to inform applied practice and research. However, the case study, itself, presented an opportunity to reflect on delivering and researching an online program during the COVID-19 pandemic. As a result, the case study includes elements of both practice and research, and has been structured and presented according to the general guidelines for Case Studies in Sport and Exercise Psychology (Cotterill, Schinke, \& Thelwell, 2017).

\section{The Case}

In order to address our first aim, Jonny initially observed and analyzed coaching behaviors of four of the nine coaches delivering the on-line program initiated by Julie following institutional ethical approval and consent from all participants. The Arizona State University Observation Instrument (ASUOI; Lacy \& Darst, 1984) is a system for categorizing coach behaviors that was employed across 10 tennis coaching sessions delivered online [Julie delivered 6 sessions independently, one coach delivered 1 session independently, one coach delivered three independently, and one session was delivered by Julie and another coach together; all coaches were insured for online delivery through their coaching accreditation] with four children aged 6-13 years old (two players participated in 1 session, one player participated in three sessions, and one player participated in 5 sessions). Coaching sessions were conducted via a video calling platform on the coaches' smartphones which allows up to four participants on the call. Coaches would arrange a mutually convenient time to call the parent or guardian and then "virtually enter" an indoor or outdoor environment of the players' home which could be indoor or outdoor. Coaches had been 
given a remit of facilitating a warm-up followed by coordination and skill-based practices that allowed the parent/guardian and player to utilize the space they had (e.g. hitting sponge balls against a wall, creating home-made nets). Jonny observed the on-line coaching sessions live and categorized coaching behaviors via the ASUOI. He also made field notes for each session. The average time per coaching session was 23 minutes and 10 seconds (range: 18-35 minutes).

Across the 10 coach sessions, 1,938 behaviors were recorded and categorized with the 14 ASUOI behavior categories. A total number of each behavior category, percentage of the total behaviors recorded per category (Use of first name is treated as an independent category; Lacy \& Darst, 1984), and rate per minute of each behavior category was calculated as follows (total number, percentage, rate per minute): Use of first name $=200,10.32 \%, 0.87$; Pre-instruction $=198$, $11.39 \%, 0.86$; Concurrent instruction $=88,5.06 \%, 0.38 ;$ Post-instruction $=134,7.71 \%, 0.58$; Questioning $=176,10.13 \%, 0.76 ;$ Physical assistance $=0,0 \%, 0 ;$ Positive modelling $=186$, $10.70 \%, 0.81 ;$ Negative modelling $=27,1.55 \%, 0.12 ;$ Hustle $=44,2.53 \%, 0.19 ;$ Praise $=340$, 19.56\%, 1.47; Scold =6, 0.35\%, 0.03; Management $=183,10.53 \%, 0.79 ;$ Uncodable $=106,6.10 \%$, 0.46 ; and Silence $=250,14.38 \%, 1.08$. The overall average rate of per minute of behaviors recorded across all coaching sessions was 7.68 (range 6.20-10.63).

In order to assess how the coaching behaviors from this case compared with face-to-face delivery of coaching sessions, published studies using an un-modified or un-adapted version of the ASUOI (i.e., the same version employed in this case study) were initially identified via reviews by Kahan (1999; studies up until 1997) and Cope, Partington, and Harvey (2017; studies from 19972016) and post-2016 research identified through database searches. A synthesis of the published studies identified (Claxton, 1988; Croad \& Vinson, 2018; Cushion \& Jones, 2001; Isabel, Antonio, Antonio, Felismina, \& Michel, 2008; Potrac, Jones, \& Armour, 2002; Potrac, Jones, \& Cushion, 2007; Roberts, Fairclough, Ryrie, \& Sharpe, 2012) allowed for an average percentage for each behavior to be calculated, as follows: Use of first name $=11.43 \%$; Pre-instruction $=10.88$; 
Concurrent instruction $=17.22 \%$; Post-instruction $=14.46 \%$; Questioning $=3.59 \%$; Physical assistance $=0.81 \% ;$ Positive modelling $=3.14 \%$; Negative modelling $=1.04 \% ;$ Hustle $=5.37 \%$; Praise $=10.51 \% ;$ Scold $=1.81 \% ;$ Management $=7.99 \% ;$ Uncodable $=4.67 \%$; and Silence $=18.23$ Figure 1 presents a comparison of the coaching behaviors in our case study with previously published studies involving face-to-face coaching sessions. Few published studies (e.g., Claxton, 1988) reported rate per minute of behaviors recorded across all coaching sessions, preventing a meaningful comparison.

In order to address our second aim (to investigate the perceived effectiveness of remote, online tennis coaching sessions), surveys were completed following ethical approval with all the coaches (all adults) involved in the delivery $[\mathrm{N}=9 ; 4$ female/5 male, average age $34.44,10.5$ average years coaching experience, average sessions delivered $(M=5.11, \mathrm{SD}=1.59)$; level of coaching qualification $=$ Level $1(n=1)$, Level $2(n=3)$, Level $3(n=2)$, Level $4(n=1)$, Level $5(n=2)$ (Lawn Tennis Association, 2020)]; all coaches were insured for online delivery through their coaching accreditation), and 13 of the 16 parents/guardians (all adults) of children [average age $=$ 10.21 , average number of sessions $=3.85$ ) who participated in at least one on-line coaching session.

The coaches were asked the following question on a Likert-scale, with anchors of extremely comfortable (5) and not comfortable at all (1): How confident were you in delivering the online sessions. This resulted in a score of $3.44(\mathrm{SD}=0.5)$.

When asked in an open-ended question, If anything, what did you enjoy or what do you feel went well during your online sessions? the coaches reported they enjoyed "staying connected", having the opportunity to "build a relationship between family and coach" and that it was a "creativity challenge".

When asked in an open-ended question, Were there any limitations or issues with the online delivery? the main issue involved a different kind of connection (i.e., wifi): "at times, the lesson could be disrupted by a poor connection, and it might take longer to explain 
things". They also reported it was harder to demonstrate activities due to "limitation of space when in a small room in the house" as well as technical issues such as those with quality of the video and camera angles.

When asked, Would you be open to online delivery like this in the future? 100\% of coaches responded "Yes". In the open-ended comments to this question, coaches mentioned how they would improve their delivery if they were to do it again as reflected in this quotation from one coach: "I think maybe the 'flow' of the lesson could be improved by the players being aware of what they will be doing (drills, etc.) before the lesson and then the coach could take on more of supervisory role as opposed to trying to demonstrate too many things over video call."

The questions and results of the parent/guardian survey were as follows: How useful did you find the online sessions as a parent? [Likert-scale, with anchors of extremely useful (5) and not useful at all $(1)=4.46(\mathrm{SD}=0.5)]$; How useful were the follow-up instructions/sessions? [Likertscale, with anchors of extremely useful (5) and not useful at all $(1)=4.46(\mathrm{SD}=0.5)]$; Did your child/children practice in between sessions? = a great deal $(\mathrm{n}=3)$, a lot $(\mathrm{n}=2)$, a moderate amount $(\mathrm{n}=8)$; and Did you learn new skills, drills, or games to practice with your child? $=100 \%$ (yes).

When asked, Were there any limitations or issues with the online delivery? the majority of parents/guardians answered "No". As with the coaches the parents highlighted issues with wifi and technology, adding a further limitation "that we had to keep going back to screen to get instructions". Overall, the parents tended to respond to the question of limitations in a positive way with comments such as "the sessions were adapted to the outdoor areas we used" and "it is not as good as face to face but definitely better than no sessions." One parent commented that although it was good for the child to keep contact with her coaches “...I think she prefers the human contact and interaction with her coaches, friends, and peers". 
When asked, Would you be open to online delivery like this in the future? $100 \%$ of parents/guardians answered "Yes" with parents emphasizing it had helped with skill development, e.g. "She worked a lot on her chopper grip and footwork throughout the sessions and she is definitely more confident with both of them, especially chopper grip".

In order to address our final aim (to identify key factors to inform applied practice and research), a focus group was conducted by Jonny and Julie following ethical approval with the nine coaches who delivered the programme and completed the coach survey (demographics above). All coaches volunteered to participate and were given the opportunity to freely withdraw at any point. The focus group was conducted and recorded online via a password protected video technology system and lasted 1 hour and 18 minutes. A semi-structured questioning schedule developed from log notes collected by Jonny as part of the on-line coaching session observations helped moderate the focus groups (Phillippi \& Lauderdale, 2018). The questions focused on what went well, what could be improved, coaching behaviors, modelling and questioning, structure of session, engagement and motivation of participants, engagement and motivation of parents, and general reflections. David checked the schedule to ensure the questions were understandable and would encourage discussion.

In line with our philosophical approach, we conceptualized the focus group as a "research site, not a research instrument" (Hollander, 2004, p. 631). The focus group was recorded and transcribed verbatim. Jonny and Julie each read and reread the transcripts and extracted illustrative quotes through ethnographic analysis (cf. Ryan, Gandha, Culbertson, \& Carlson, 2014; Wilkinson, 1998) that helped inform applied practice and research. The key factors identified included staying connected during the pandemic, supporting and maintaining motivation, and creativity.

The first key factor identified was the importance of staying connected during the pandemic as highlighted by a coach:

I thought, first and foremost, the main thing is it's not that it doesn't matter, but in some ways 
it almost didn't matter what we did. The main thing is we're making touch, making contact and showing that we care.

Although the core reason for the online coaching was to facilitate tennis practice at home, all the coaches recognized social connection was important. Throughout the case study the coaches used questioning as a behavioral technique to build this social connection. In fact, there was more questioning behavior used online when compared to standard face-to-face delivery (cf. Claxton, 1988 [10.15\% vs 5.95\%), and this was supported by the focus group. However, much of this questioning was not specifically related to any performance variables in the sport. Rather, many of these questions related to the young athletes' wellbeing and were aimed at maintaining or improving the pre-existing coach-athlete relationship. An experienced coach highlighted the reason for these types of questions:

The key thing is the connection that we're making... you get to know the player, you really got to get to know them, and it's so individual to know what makes them work...And so this is an opportunity. Another opportunity for us to get to know them a little bit better...before any real coaching can happen, you have to be connected. You know they have to trust you, they have to like you. They have to believe that you care.

This quote highlights the importance of connection and trust in the coach-athlete relationship. It is of note that this coach believed the restrictions imposed by the pandemic were a unique opportunity to improve this relationship, not just maintain it. This finding is supported by Gould, Nalepa and Mignano (2020) who emphasize the importance for coaches of younger athletes within the online environment in building trust within the relationship. Coaches in this case study viewed this as crucial for the development of technical and social skills required in sporting performance. Retaining trust and building upon the coach-athlete connection can be achieved by asking appropriate questions that are not performance related. It is possible that this type of questioning shows an interest in the person behind the athlete and could help to facilitate a connection as hinted 
by an experienced coach:

If you've had the experience of trying to coach someone when you don't really know them that well or you haven't quite got a relationship, it's just so difficult, unbelievably difficult. And yet when, when you have made that connection, it just flows.

Positive modelling was viewed by the coaches as a vital behavior to develop connection. The rate of positive modelling by the coaches in this case is higher than in previous studies investigating coach behavior in tennis (cf. Claxton, 1988; $10.70 \%$ vs $3.88 \%$ ). Conversely, there were no significant differences in negative modelling compared to standard face-to-face delivery. The coaches acknowledged that this was a conscious change in behavior that they used to work within the environment. One of the more experienced coaches explained their decision to use positive modelling instead of sharing videos of an elite tennis player with an athlete they coached: I had these Nadal videos and I sent them to the kids, ach I'm not really sure if they're that interested, but if I'm demoing the Nadal drill on the grass outside and ask them to go and do it, then they get stuck in about it and I think it's that connection that inspires them to do it. Rather than watch the coaches who had worked with a world number one player demonstrate the drills, the players preferred to see their coach demonstrate live. The coach explained that:

it's maybe more interesting for the kids to see one of us demoing it rather than watching a random person on a...video doing the demo, because at first I thought I'll just send them the videos but actually I think it's quite powerful that we do it.

The coaches explained this as a tangible way they could demonstrate that they cared, thus building the connection with their players. Another experienced coach in the focus group used a different type of modelling behavior, including pre-prepared videos and screen shots to aid understanding:

I sent a video of myself doing what she's doing and then doing what I thought would be a bit 
better so like with her serve, her elbows up. So, I sent her a photo of that [mirroring on the screen these movements] and then they sent a photo of the elbow down and kind of highlighted it with drawing.

Although not live modelling this coach also came to realize that using herself as a model, as opposed to a pre-existing online resource, was perceived as more powerful and a means of connection by her player.

It would appear that not only were coaches motivated to stay in touch and get to know their players more, but many of the coaches also personally benefited from staying in touch with players and families.

It's quite good fun actually as well, like seeing him practising and all his wee trick shots and stuff like that and, you know, helping them maybe come up with new games but you get new ideas from them and stuff as well.

This coach was also enjoying the experience and perhaps the experience was also helping them through this difficult pandemic period. This idea of what the coaches were personally gaining from the experience is explicitly stated by an experienced coach who said, "I really enjoyed it myself as well. I think it [is] brilliant for connection, not just with the parents and families but also with all of you [the coaches]".

The coaches also reported the continued communication and connection with the parents and guardians was important, as illustrated in this quotation: "but I actually think what's so good about it is that it's just like a nice way to stay connected with the player, and even like the parent."

The second key factor identified was how to support and maintain motivation. Coaches described setting mini goals or timing players to complete activities as examples of strategies they used to increase motivation to practice in session. For example, during task orientated activities they might raise motivation by asking questions like, "how many can you get without making a mistake?" Coaches also used these strategies "to motivate them even between sessions in a way that 
maybe I don't normally in normal coaching'. Training the players at home led the coaches to see new ways in which they could motivate them to practice at home in between sessions. Empowering the players to practice between sessions was viewed as a way of motivating young athletes and improvement was seen by the coaches as a result:

just holding the racket and doing different stuff it just really helps with your coordination and if you do even like five minutes every day, which I think quite a lot of these kids probably are doing at the moment...I think you can see such an improvement in such a short amount of time just like doing like 5-10 minutes every single day so I think this program has helped show them like the different, like, em opportunities that they have, that they may be normally wouldn't because they're so busy.

It would appear the context of the pandemic, including the enforced staying at home, resulted in an increase in motivation to acquire and improve skills compared to normal life.

As the program developed, many of the coaches reported moving from a controlled style of delivery to a more autonomy support style (Ryan \& Deci, 2017). For example, one of the coaches explained how he adapted to the loss of control as an online coaching session progressed:

I think as while it's positive that they get more input and structure this session you also lose a bit of control as a coach, I think one video call started and they'd already started doing racket stuff and I kind of had like a dynamic warmup prepared and you never really have that issue on a court but you're hardly going to say to the kid like put down the racket and let's do some racquet free stuff so it's kind of weird.

While acknowledging this loss of control, the same coach recognized that by giving more autonomy to the player, they also increased motivation levels:

I would say he was more engaged when he started the lesson how he wanted to...he definitely saw more value in what he was doing if he was more guiding himself. And then I was just giving him a nudge in the right direction sort of thing. 
As the program progressed, many of the coaches reported that a "less is more" approach during the video sessions was beneficial:

I felt like the first couple I did, I was doing like 5, 5/6 things and the more I went on the less I would do, just because I think the simpler the better you know... I think like just sticking to those two/ three things worked much better in my opinion, because I think, as soon as you say go and do this, this, this, this and this, but they're sort of maybe aren't as motivated and becomes a little bit more heavy for them.

This was corroborated by another coach who, as she gained more experience in online coaching, reported that the structure became more fluid: "A lot of the session revolves around what do you enjoy? How can we expand on that?" The coaches recognized that a fixed structure helped them to get the online programme started, but as time went on they had to adapt their mode of delivery to become more fluid.

Enjoying the activities was recognized as a key factor by coaches in ensuring the athletes maintained motivation:

It was more about what they enjoyed, so they, they really liked showing the things that they've enjoyed so [one athlete] loved skipping and [another athlete] was really enjoying the swing ball. So, even though I had more things planned...I think they enjoyed showing the things that they enjoy doing throughout the time that we're not like on the call with them. So, I thought that was nice to see what they like.

Other sources of motivation that were reported came from the parents who acted as the intermediary between the coaches and tennis players. One coach found that coaching through the parent who had no prior tennis experience was a barrier to effective coaching and motivating her player. This problem was quickly solved when the directions were communicated to the player: ...her dad had headphones on and he said "she never listens to me whenever I say anything" so then he put the headphones on her and instantly when she heard it from 
someone else she did it straightaway so that just so quickly proved that if I was able to speak to her a bit more, it would have made quite a big difference.

Parental influence, while often useful for a coach, can prove counterintuitive to what the coach and athlete are trying to achieve (Jowett \& Timson-Katchis, 2005). However, in this instance the parent was trying to relay information to the player from the coach, essentially "becoming" the coach themselves. Although the message communicated was not changed, it had to come directly from the coach to have any impact on the athlete.

Many of the coaches reported that the experience of online coaching helped to strengthen their relationships with parents and guardians, and they saw it as a way of helping the tennis players by empowering the parents with more knowledge to help. Coaches were also grateful for "the positive parental kind of motivation" that they experienced during the video sessions and recognized that the context of the coaching during the pandemic could be attributed to more effective relationships between the coach, tennis player, and parent as illustrated as follows:

...[the parent] intervened during one of the calls and said they were having an issue with the backhand and [the coach] knew from Sundays that [the tennis player] struggles with the backhand....but once [the parent] spotted it, he kind of liked engaging with that aspect of his game more....so I think that's something that is maybe good to have that secondary person in the call.

The coach here was referring to "normal" coaching on a Sunday with another coach when he perhaps can't engage the player to practice the backhand. However, the context of the online coaching whereby the parent was explicitly involved in the session led to more engagement in the practice the coach wished to promote.

Online coaching was delivered to families who had only one child and to families who had more than one child at home. One coach compared the different ways she could motivate sibling groups compared to her experiences coaching a child on their own: 
It felt like a little bit more motivation I guess from [one sibling] and [second sibling] when they knew that they were competing with each other, compared to, I mean [one tennis player who is coached individually] always works hard...[second tennis player who is coached individually] as well but I think it's a different kind of motivation, I guess.

The coach recognized that the element of competition she could inject when coaching the siblings over the phone was different to coaching the individual children.

The third, and final, key factor identified involved creativity. Technology presented the greatest challenge to the coaches in the delivery of the program. The calls were made via a video calling system and many coaches reported technical issues with this mode of delivery, for example:

I think probably [the system] would have been better with the quality. Because [the video calling system] sometimes when they're outside...it would get like what you're saying like grainy and stuff and like sometimes I couldn't really see what they were doing.

Rather than view this as a problem, the coaches used creativity and treated this challenge as an opportunity to "think out of the box". Most coaches created videos for the children in advance and in-between sessions. One coach describes how this process worked for her and her player:

...she sent me a few videos. And I kind of sent feedback for that and I think like that way was easier for the technical side, because you can take your time and kind of explain things and send things a bit more clearer than trying to explain that just on a call.

Another challenge that the coaches faced was the space they had to deliver from and to (i.e., the coaches were delivering from small gardens and living rooms to small gardens and living rooms). One coach seemed surprized by his own creativity, commenting, "it's amazing how much you can come up with even in limited space" while another coach described the difficulties of delivering from a limited space and her strategies to combat this:

I thought that it would be very difficult to explain different drills and stuff, especially when you're using your phone, like the screen is like a long rectangle so it's hard like if you're 
doing a serve or something half of your body's out of it. A lot of time at least for me, but a lot of the time I was able to explain some of the drills, just with small, small demos or with just with words. There are a couple times where it's a bit difficult in terms of like placing the people. If you go here, you go there sometimes telling them to go in different positions that was a little bit trickier but overall the communication was easier than I thought it would be. In spite of the limits of her own space, this coach described how she employed teaching techniques other than modelling, for example using words only and also seems surprized that the communication was easier than she thought. Another coach explained how they used creativity to make the most of their environment:

We got round the camera issue by having the camera sort of set up at the kind of mini netpost, just behind there, and then having the parent do the drills with the child as another child would in a session. I think that kind of gave the child a new perspective in the lesson, being able to engage that way with their parents in a way they wouldn't normally during tennis. I think that was quite positive for the child.

Similar observations were echoed by another coach who reflected that the challenge of doing a quality demonstration led him to think of other ways to improve communication:

Probably the hardest thing it is when you have an idea for something and you're on your own, really difficult to demonstrate it.... because it makes you think carefully about what you say and the information that you get and anything you do say has to be clear and concise. Coaches also viewed the situation as an opportunity to upskill their own coaching abilities as illustrated in the following quotation:

I really like personally the challenge of coming up with new creative ways to teach you know different, different skills. And I think that was, that was really good from a coaching point of view to, to be able to force yourself to think of new ways and you know look on social media and look on internet because it's loads of stuff, loads of stuff online. 
Perhaps the most creative tool observed through the research was the use by one coach of a significantly smaller racket (i.e., Babolat Mini Replica Pure Drive Tennis Racket) to demonstrate technique more effectively. The racket was 9.85 " in length and 3.93 " wide compared to the normal size tennis racket (i.e., Babolat Pure Aero Team Racket; 27" in length and 10.62" wide) the coach would utilise on a tennis court. The perspective allowed positive modelling to be exhibited using a racket that could work within the technical limitations imposed by a smartphone screen.

Whether or not the modelling was pre-recorded or live, the use of a reduced size racquet could have implications for coaches of other sports who have to adapt to online delivery. It is proposed that coaches of sports that use equipment as an extension of the body to perform (e.g., badminton, squash, golf, lacrosse, hockey) could use a similar method in an attempt to model technique effectively to overcome technological limitations.

\section{Reflections}

This case study aimed to offer reflections for applied researchers and practitioners on our experiences of investigating coaching behaviors in an on-line environment. The case study, itself, also presented an opportunity to reflect on delivering and researching an online program during the COVID-19 pandemic.

Parents and coaches generally perceived the online program to be effective. Coaches also noted that the increased interaction with parents helped them to motivate their athletes to practice skills more frequently than they would normally outside the context of the pandemic. This could be attributed to the fact that families had more time which allowed them to focus more on the skills that were being presented to them by coaches.

The context of the case study enabled coaches to reflect on how they motivated their players. They reflected that, in some respects, the coaches were more effective via video calls than they were in normal coaching conditions. For example, there were more opportunities to encourage players to practice in-between sessions and they had more opportunities to communicate with 
parents, both factors that contribute to athlete motivation (Ryan \& Deci, 2017). From the athlete point of view, the coaches concluded that giving athletes more control of their sessions and ensuring they were enjoying the activities increased motivation. It also appeared that parental input can have both a positive and negative impact on motivation and having a sibling to participate with and compete with during the sessions also contributes to increased motivation.

There were benefits of staying in touch with players and parents as a way of supporting families during the pandemic. This led coaches to reflect on wider issues around coaching in general such as the importance of connecting as an antecedent of effective coaching and the importance of modelling, as well as their own role in that once a relationship had been established. Although coaches were often motivated to show that they cared through this online programme, there were also benefits for the coaches themselves in taking part in terms of connection with families and other coaches.

As a result of being a trainee sport and exercise psychologist with a grounding in a personcentred approach to practice, Julie has reflected that just "being there" via the online project for participants during the pandemic facilitated relational depth across a number of networks. This notion of relational depth refers to human connectedness, a type that transcends a particular set of skills and is about the kind of care and commitment that goes beyond the usual level of professionalism required of a therapist (Cooper, 2013) or in this case, coach. Although this case study focused on coaches and coaching behavior, Julie felt that her dual professional status as coach and trainee psychologist allowed her to evaluate her own experience in the case study within a humanistic framework and one which she felt was pertinent for the context of the pandemic. She had felt moments of relational depth in the network of relationships that had arisen for her within the case study (i.e., coach-athlete, coach-parent, coach-coach, and researcher-researcher) as a result of supporting others and being supported.

Both parents and coaches highlighted the impact of technology throughout the program with 
regard to the quality of the wifi connection, video system calls, and the physical limitations of delivering through a smartphone. This was deemed a limitation of the program and the coaching team reflected that they would need to improve their own personal set-up to deliver from (e.g., perhaps use a bigger screen, better software) and also set up their own space more effectively (e.g., with a tripod or bigger area in order to be able to deliver better quality demonstrations). Although many of the coaches discussed how they found creative ways to deliver technical points and help facilitate activity in small spaces (e.g., prerecording videos and sending to athletes in advance), the context of the pandemic - where participants on both sides of the camera were having limited interaction with anyone outside their home - led to the social connection having greater impact for everyone involved.

Following the conclusion of the case study, some online coaching continued for a further four weeks (due to extended quarantine restrictions). Julie's reflection as a coach is that some athletes became less engaged, and there was a risk of turning a positive experience into an alienating experience. One possible explanation for this could be that although the coach and athlete are co-present (Schultze \& Brooks, 2019), the coach is facilitating a focused interaction with a parent and child(ren) as opposed to between a coach and child(ren) as would happen normally. Some of the young athletes were potentially being alienated by the online sessions both because delivery was through a parent and also through a loss of haptic engagement, which can dampen the sense of copresence (Zhao, 2003). Jonny noted this was particularly the case with children under the age of 10 , so it is important to monitor athlete perceptions over time in relation to age (cf. Bennet, 2020). At this stage in the pandemic it is too early to know how long face-to-face delivery coaching will have to be complimented and/or replaced by online delivery. If it were to continue for a lengthy duration, coaches would need to give thought to keeping the sessions varied and interesting in order to maintain motivation and compliance with such sessions. This is not to say that online coaching sessions have a shelf life; online coaching sessions have been shown to be a useful means of 
maintaining a coach-athlete relationship and improvements in performance when there are other factors such as distance involved (Bennett, 2020).

One of the aims of this paper involved the analysis of coaching behaviors online. We believe measuring and quantifying coach behaviors in online environments is indeed possible, and would recommend further research in this area. By using the ASUOI (Lacy \& Darst, 1984), Jonny was able to code behaviors accurately and allow comparison to field-based studies (Figure 1). There was one category (physical assistance) that was not possible to be exhibited on online delivery as the coach is not physically present in the same environment as the athlete. However, another behavior that coaches exhibited was the sharing of videos (both pre-recorded and live) to demonstrate technique of various skills. We classified this as either positive or negative modelling as it was the most appropriate category. Due to the ASUOI (Lacy \& Darst, 1984) not being designed for use in such a unique coaching environment and the likely increase in virtual coaching as a result of social distancing implications, we recommend employing "Video Share: Positive" and "Video Share: Negative" in place of Physical Assistance. While these are both similar to the retained "Positive Modelling" and "Negative Modelling" categories the coach may not be the individual demonstrating the technique in the video. This nuanced difference is important as the online environment has limitations for modelling, such as the size of screen or the physical environment the coaches find themselves in when delivering (Bennett, 2020).

This further supports the notion that coaches are incredibly creative and adapted well to the situation. While this was evident with regard to the athletes, it was also supported by the parents who agreed that the methods employed by coaches helped increase engagement of the participants. The participants being coached in this study were aged between 6-13 years old, and it is likely that they are comfortable with technology and this can be used to engage them. This is further supported by Gould et al. (2020) who believe that athletes' increased competence with technology is a significant strength that should be harnessed by coaches to improve performance variables as well 
as enhance an existing coach-athlete relationship. As highlighted earlier, creative methods incorporating technology such as this could be used by coaches irrespective of the physical coaching environment.

While there has previously been a reluctance to include technology in the coaching process (Parker et al., 2012), Generation Z athletes can be more comfortable with technology (Gould et al., 2020) and this case study highlights that they would be open to use of this sort of practice on a more frequent basis. From observing each session, it was clear that the coaches and parents initially struggled with certain aspects of technology. As the project progressed more familiarity was achieved by coaches and parents and this led to sessions that were delivered with less interruption and more clarity which benefitted the young athletes. It is suggested that coaches who wish to deliver in an online environment familiarize themselves (perhaps with other coaches, friends, family, or parents of young athletes) with the technology prior to delivery to participants. We also suggest coaches ensure, as much as possible, that their physical environment is suited to online delivery. Factors such as lighting, weather, positioning of camera(s), and audio clarity should be considered to ensure a quality session can be effectively delivered. There are challenges to address all of these factors; however, if athletes can see that the coach is making the effort, they may be more likely to engage with the session.

Once coaches, parents and athletes become familiar and proficient with technology and online delivery there is a chance for meaningful sessions to take place within sports. We also suggest that coaches who work, or will work, with younger athletes in an online coaching environment try to achieve direct communication with the athlete rather than deliver via the parent or guardian after obtaining consent.

Following COVID-19, coaches will have to be adaptable to maintain relationships with their athletes and limit, almost inevitable, decreases in performance level. The coaches in this case study attempted to do this using video technology and incorporating parents into the process due to the 
age of the athletes. This provided a unique research opportunity to investigate how this change in environment would affect how coaches behave. From our perspective, some of the coaches displayed exceptional creativity to allow this to happen. Each session was entirely different and tailored to the environmental demands of each individual athlete. This was not simple to achieve, as there were many technical difficulties in this process that coaches found unique solutions to overcome. While the behaviors exhibited varied in frequency and style from previous studies, the coaches were trying to achieve the same goal as they normally would with this group of athletes, i.e., improving performance and helping their athletes to enjoy the sport. They managed this by building upon existing relationships they had with athletes and parents and embracing technology to deliver quality sessions that were well-received by the parents of the young athletes. Athletes are becoming more proficient with technology and this should be harnessed as a way of increasing their engagement and performance in sport. This can happen if coaches are willing to embrace technology and learn from the limited research that has been conducted into this field so far. It is proposed that more research needs to be conducted into this area, including longitudinal studies investigating if and how coach behaviors change over time in this environment. Further research with coaches of team sports in online environments is also recommended, although this is likely to be more challenging due to the increased coach-athlete ratio compared to this case study.

As well as implications for coaches working with athletes there are also potential implications for coach educators. Research including Glen and Lavallee (2019) has indicated that online resources are becoming more prevalent for coach education and there is a desire to improve the quality and quantity of online resources. The COVID-19 pandemic has caused significant issues for face-to-face delivery that has also impacted traditional coach education delivery, however, many organizations around the world have continued to deliver their coaching qualifications and other continuing professional development online. Previously mentioned considerations for coaches, such as ensuring their environment is suitable and keeping delivery simple and varied could also be 
applicable to coach education across a variety of sports to ensure quality of delivery and the motivation of participants.

It would appear the context of the COVID-19 pandemic made it easier in several ways to conduct a case study into coaching and coach behaviors. Our reflections on this "case study within a case study" were that the delivery and research was relatively more straightforward than we previously experienced with everyone based at home. For example, Jonny and Julie had attempted to organize a similar research study pre-pandemic and experienced several barriers including weather cancellations and travel time Jonny needed to observe the coaching team at the club (they lived in different cities). We feel the design of this case study was easier to implement because communication was improved as a result of the online discussions prior to the observations. It was easier to connect with each other and have discussion pre- and post-online observation sessions; something that would not be possible in a regular coaching environment where coaches often conduct back-to-back sessions with little time for reflection-on-action. We believe the nature of the online delivery actually enhanced the quality of pre-session preparation and subsequent coach reflections.

We also note the ease with which we were able to collect data via online questionnaires and to set-up and record a focus group online. With the coaching team based at home, the participants were happy to meet virtually and contribute to the research. We believe the focus group, itself, was a positive experience for the coaching team, bringing them together with a shared purpose to contribute what they had learned to the project. In the context of the pandemic, the focus group provided another opportunity for meaningful connection.

Finally, the three of us experienced an evolving and developing connection through the act of collaborating on this case study, itself. With the three of us at home and able to virtually "meet" regularly through video calls, the case study progressed with pace. Our relationship developed through regular meetings that would not have been possible pre-pandemic due to barriers of time 
and distance. We all agree that throughout the production of this case study, from design to writeup, the key factors staying connected, supporting and maintaining motivation, and creativity were experienced not just by the athletes, parents, and coaches, but also by us. The journal, Case Studies in Sport and Exercise Psychology, also stayed connected in a very timely manner throughout the pandemic, helped maintain motivation through the review process, and afforded us the opportunity to be creative in structuring our manuscript outside of the traditional guidelines by combined research and professional practice in our case study within a case study. 


\section{References}

Bennett, B. C. (2020). My video coach: A phenomenographic interpretation of athlete perceptions of coaching through a live video feed. Qualitative Research in Sport, Exercise and Health. DOI: 10.1080/2159676X.2020.1733643

Child Protection and Sport Unit (2020). Remote teaching and coaching. London: NSPCC. https://thecpsu.org.uk/resource-library/best-practice/remote-teaching-and-coaching/

Claxton, D. (1988). A systematic observation of more and less successful high school tennis coaches. Journal of Teaching in Physical Education, 7, 302-10. https://doi.org/10.1123/jtpe.7.4.302

Cooper, M. (2013). Experiencing relational depth in therapy: What we know so far. In R.Knox, D. Murphy, S. Wiggins, \& M. Cooper (Eds.), Relational depth: New perspectives and developments (pp. 62-76). London: Palgrave Macillian.

Cope, E., Partington, M., \& Harvey, S. (2017). A review of the use of a systematic observation method in coaching research between 1997 and 2016. Journal of Sports Sciences, 35, 2042-2050. https://doi.org/10.1080/02640414.2016.1252463

Cotterill, S. T., Schinke, R. J., \& Thelwell, R. (2017). Writing manuscripts for Case Studies in Sport and Exercise Psychology. Case Studies in Sport and Exercise Psychology, 1, 1-3. https://doi.org/10.1123/cssep.2016-0009

Croad, A., \& Vinson, D. (2018). Investigating games-centred pedagogies to enhance athlete decision making in elite coaching contexts. International Journal of Coaching Science, 12, 35-68.

Cushion, C. J., \& Jones, R. L. (2001). A systematic observation of professional top-level youth soccer coaches. Journal of Sport Behavior, 24, 354-376.

Glen, J. \& Lavallee, D. (2019). How do coach educators influence meaningful behavior change in sports coaches? Kinesiologia Slovenica, 25 (3), 16-30.

Gould, D., Nalepa, J. \& Mignano, M. (2020). Coaching Generation Z athletes. Journal of Applied Sport Psychology, 32, 104 120. https://doi.org/10.1080/10413200.2019.1581856 
Hollander, J.A. (2004). The social contexts of focus groups. Journal of Contemporary Ethnography, 33, 602-637. doi:10.1177/0891241604266988

Isabel, M., Antonio, S., Antonio, R., Rosado, F., \& Michel, M. M. (2008). A systematic observation of youth amateur volleyball coaches behavior. International Journal of Applied Sports Science, 10, 37-59.

Jowett, S., \& Timson-Katchis, M. (2005). Social networks in sport: Parental influence on the coach-athlete relationship. The Sport Psychologist, 19, 267-287.

https://doi.org/10.1123/tsp.19.3.267

Kahan, D. (1999). Coaching behavior: A review of the systematic observation research literature. Applied Research in Coaching and Athletics Annual, 14, 17-58.

Lacy, A. C., \& Darst, P. W. (1984). Evolution of a systematic observation system: The ASU coaching observation instrument. Journal of Teaching in Physical Education, 3, 59-66. https://doi.org/10.1123/jtpe.3.3.59

Lawn Tennis Association (2020). Coach accreditation. London: Author.

https://www.lta.org.uk/globalassets/coach/documents/accreditation/coach-accreditation-guide2020.pdf

Nelson, L., Cushion, C. J., Potrac, P., \& Groom, R. (2014). Carl Rogers, learning and educational practice: Critical considerations and applications in sports coaching. Sport, Education and Society, 19, 513-531.

Parker, K., Czech, D., Burdette, T., Stewart, J., Biber, D., Easton, L., Pecinovsky, C., Carson, S., \& McDaniel, T. (2012). The preferred coaching styles of generation Z athletes. Journal of Coaching Education, 5(2), 5-23. https://doi.org/10.1123/jce.5.2.5

Phillippi, J., \& Lauderdale, J. (2018). A guide to field notes for qualitative research: Context and conversation. Qualitative Health Research, 28, 381-388.

https://doi.org/10.1177/1049732317697102 
Potrac, P., Jones, R., \& Armour, K. (2002). 'It's all about getting respect': The coaching behaviors of an expert English soccer coach. Sport, Education, and Society, 7, 183-202. https://doi.org/10.1080/1357332022000018869

Potrac, P., Jones, R., \& Cushion, C. (2007). Understanding power and the coach's role in professional English soccer: A preliminary investigation of coach behavior. Soccer and Society, 8 , 33-49. https://doi.org/10.1080/14660970600989509

Roberts, S. J., Fairclough, S.J., Ryrie, G., \& Sharpe, L (2012). A computer-based observational analysis of physical education teachers and youth sport coaches pedagogic behavior. International Journal of Performance Analysis in Sport, 12, 498-506. https://doi.org/10.1080/24748668.2012.11868614

Ryan, R. M., \& Deci, E. L. (2017). Self-determination theory. New York: Guilford Press.

Ryan, K. E., Gandha, T., Culbertson, M. J., \& Carlson, C. (2014). Focus group evidence: Implications for design and analysis. American Journal of Evaluation, 35, 328345. https://doi.org/10.1177/1098214013508300

Schinke, R. J., McGannon, K., \& Smith, B. (Eds.). (2014). Community based research in sport, exercise and health science. Oxfordshire, UK: Routledge.

Schultze, U., \& Brooks, J. A. M. (2019). An interactional view of social presence. Information Systems Journal, 29, 707-737. https://doi.org/10.1111/isj.12230

United Kingdom Government (2020). Coronavirus (COVID-19): What you need to do. Retrieved on 23 March 2020 from https://www.gov.uk/coronavirus

Vygotsky, L. S. (1978). Mind in society. Cambridge, MA: Harvard University Press. Wilkinson, S. (1998). Focus group methodology. International Journal of Social Research Methodology, 1, 181-203. https://doi.org/10.1080/13645579.1998.10846874

Zhao, S. (2003). Toward a taxonomy of copresence. Presence, 12, 445-455. 


\section{Figure Caption}

Comparison of coaching behaviors during the COVID-19 pandemic with previously published studies involving face-to-face delivery of coaching sessions that employed an un-modified or unadapted version of the Arizona State University Observation Instrument (ASUOI). 


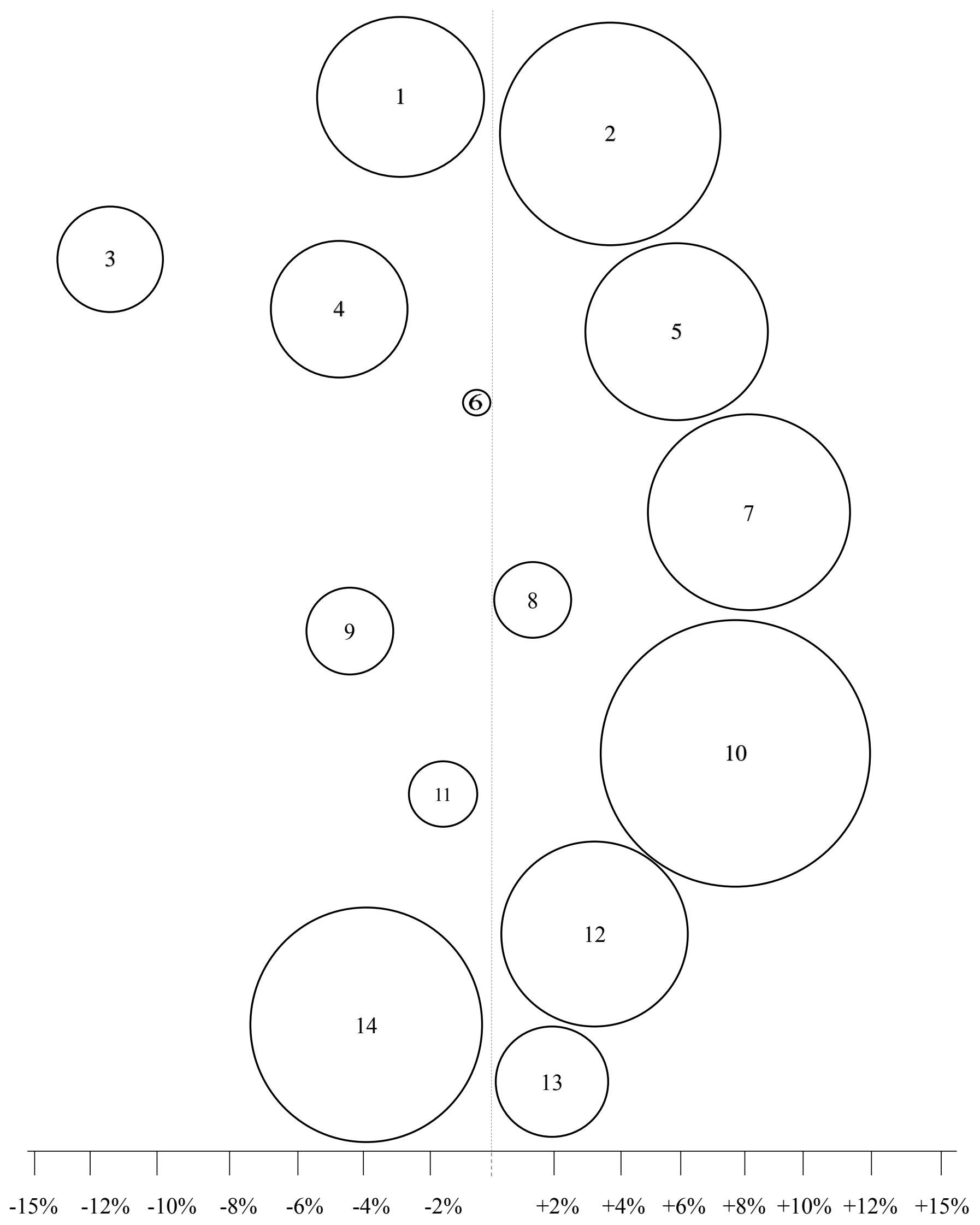

Note. 1 = Use of first name; 2 = pre-instruction; $3=$ concurrent instruction; 4 = post- instruction; $5=$ questioning; $6=$ physical assistance; $7=$ positive modelling; $8=$ negative modelling; $9=$ hustle; $10=$ praise; $11=$ scold; 12 = management; $13=$ uncodable; $14=$ silence. Dashed line indicates mean percentage across previous studies. Bubble area indicates frequency of occurrence. Bubbles to the right of the dashed line had more recorded behaviors in online coaching compared to face-to-face, and the opposite for bubbles to the left of the dashed line. 